\title{
A novel micro-solid oxide fuel cell ( $\mu$-SOFC) for detecting methane content in biogas
}

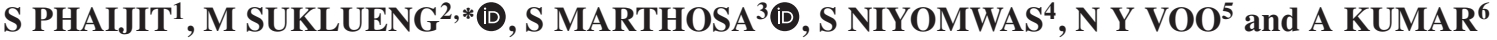 \\ ${ }^{1}$ Energy Technology Program, Faculty of Engineering, Prince of Songkla University, Hat Yai, Songkhla 90110, Thailand \\ ${ }^{2}$ PSU Energy Systems Research Institute (PERIN), Interdisciplinary Graduate School of Energy Systems, Prince of \\ Songkla University, HatYai, Songkhla 90110, Thailand \\ ${ }^{3}$ Faculty of Science and Industrial Technology, Prince of Songkla University, Suratthani Campus, Surat Thani 84000 , \\ Thailand \\ ${ }^{4}$ Department of Mechanical Engineering, Faculty of Engineering, Prince of Songkla University, HatYai, Songkhla 90110, \\ Thailand \\ ${ }^{5}$ Centre for Advanced Material and Energy Sciences (CAMES), Universiti Brunei Darussalam, Jalan Tungku Link, \\ Gadong BE1410, Brunei Darussalam \\ ${ }^{6}$ Department of Mechanical Engineering, Delhi Technological University, Delhi 110042, India \\ *Author for correspondence (montri.su@psu.ac.th)
}

MS received 10 May 2018; accepted 19 December 2018; published online 25 April 2019

\begin{abstract}
A novel micro-solid oxide fuel cell ( $\mu$-SOFC), with a rectangular saw-tooth shape, was designed with a $50 \mathrm{wt} \%$ $\mathrm{BYCF}+50 \mathrm{wt} \% \mathrm{GDC}_{10}$ cathode and a $60 \mathrm{wt} \% \mathrm{NiO}+40 \mathrm{wt} \% \mathrm{GDC}_{10}$ anode deposited on a $\mathrm{GDC}_{10}$ electrolyte substrate by the spray pyrolysis technique. $\mu$-SOFC receives methane only $\left(\mathrm{CH}_{4}\right)$ as fuel gas from one side. The fuel gas was applied at a flow rate of $0.21 \mathrm{~min}^{-1}$. The power density obtained was $1.0 \mu \mathrm{W}$ at $800^{\circ} \mathrm{C}$. Voltage levels generated by the $\mu$-SOFC at 40-99.99\% $\mathrm{CH}_{4}$ was highly accurate representing the quantity of $\mathrm{CH}_{4}$. Low accuracy was observed at $10-30 \%$ of $\mathrm{CH}_{4}$. Therefore, $\mu$-SOFC is an application of SOFC technology to be a sensor for economically detecting $\mathrm{CH}_{4}$ in a biogas system, while being capable of operating in humid conditions at high temperatures.
\end{abstract}

Keyword. $\mu$-SOFCs; BYCF cathode; methane; biogas; sensor.

\section{Introduction}

A methane $\left(\mathrm{CH}_{4}\right)$ concentration in biogas of $\sim 60-70 \%$ [1,2] enables us to convert $\mathrm{H}_{2}$ by a reforming process which further can be converted into electricity by a fuel cell. Thailand is the world's largest producer of dry natural rubber [3]. The waste water from oil palm, and rubber can be used to produce biogas [4]. $\mathrm{CH}_{4}$ is one of such biogases produced which could be used as a possible alternative fuel in the drying process. The direct methane use is challenging as the fuel processing system needs to convert hydrocarbons into hydrogen for the fuel cells [5]. The gaseous components and composition of biogas depend on the operating conditions, raw materials, retention time and temperature [1]. Hence, the quality and quantity of biogas vary widely [3]. Particularly, the biogas steam reform technique is operated at temperatures $700-900^{\circ} \mathrm{C}$ with a $\mathrm{CH}_{4} / \mathrm{CO}_{2}$ molar ratio of $1-1.5$ with a yield of around $50 \% \mathrm{H}_{2}$ [6]. Steam reform uses high temperatures of equal to or greater than $850^{\circ} \mathrm{C}$ to excite the chemical reaction in the presence of a $\mathrm{Ni}$ catalyst. At lower temperatures, this catalyst which proved efficient in steam reforming reactions is not sufficient to activate the chemical reaction [6]. This gas reform needs a sensor which can sustain at high temperatures. Micro-solid oxide fuel cells ( $\mu$-SOFCs) are electrochemical conversion devices that could support portable equipment such as laptop computers and mobile phones [7-9].

The high power density and the ability of continuous operation for long time periods without recharge is the speciality of this device $[10,11]$. Thus, $\mu$-SOFCs are of particular interest, and more attractive due to their improved reliability and robustness with a ceramic structure [12]. They can operate at temperatures between 300 and $700^{\circ} \mathrm{C}$, which is below the range of large-scale conventional SOFCs [13]. The decrease in overall thickness of SOFCs in order to increase the activation levels of ion oxide is required to lower temperatures [14]. Electrolytes, such as gadolinium-doped ceria (GDC), have also been improved in terms of their higher ionic conductivity [15]. Cathode and anode sides of the fuel cells have also evolved with decrease in resistivity, low thermal expansion, high porosity and the ability to operate at lower temperature [16-19]. The key reaction takes place between electrons, ions and gas molecules which occurs in the interfacial layer with 


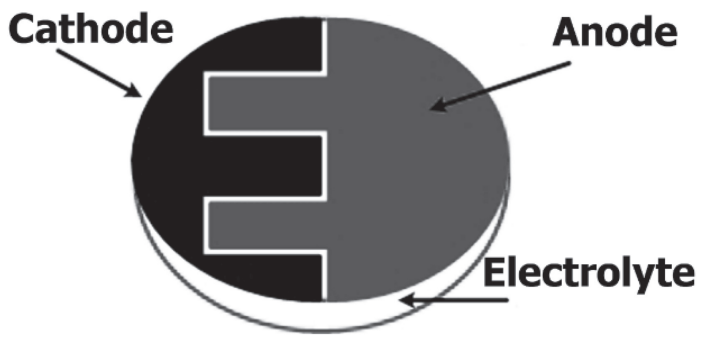

Figure 1. A novel $\mu$-SOFC for detecting $\mathrm{CH}_{4}$ in biogas.

anode/electrolyte/cathode interactions on the SOFC. Hence, the length of this triple phase boundary (TPB) should be maximized [20,21].

Suitable sensors could be used to monitor the multiple trace gases dissolved in transformer oil. The SOFC-based gas sensor is an alternative to detect $\mathrm{H}_{2}, \mathrm{CO}, \mathrm{CH}_{4}, \mathrm{C}_{2} \mathrm{H}_{6}$, $\mathrm{C}_{2} \mathrm{H}_{4}$ and $\mathrm{N}_{2}$ [22]. $\mathrm{CH}_{4}$ is a very important and dangerous flammable gas used in domestic and industrial applications. High-performance methane gas sensors have been developed from nickel oxide $\left(\mathrm{Ni}_{2} \mathrm{O}_{3}\right)$, decorated tin oxide $\left(\mathrm{SnO}_{2}\right)$ semiconducting films [23] and copper electrodes. Graphene oxide can be used to detect methane [24]. These sensors are based on materials with a high sensitivity to $\mathrm{CH}_{4}$.

This investigation aims to design a novel gas sensor using a SOFC system to detect $\mathrm{CH}_{4}$ in biogas for a reforming system. The sensor was constructed using $\mathrm{GDC}_{10}$ electrolyte as the substrate with a BYCF cathode and a nickel oxide (NiO) anode deposited on it, as shown in figure 1. The spray pyrolysis (SP) technique was used to deposit the cathode and anode layers on the electrolyte, in a rectangular saw-tooth shape, with a narrow space left between the cathode and the anode.

\section{Experimental}

A cathode composite BYCF $\left(\mathrm{Ba}_{0.054} \mathrm{Y}_{0.029} \mathrm{Co}_{1.8} \mathrm{Fe}_{0.062} \mathrm{O}_{2.89}\right)$ [25] was prepared using re-agent grade metal oxide powders from Sigma Aldrich, Germany. A mixture of $5 \mathrm{wt} \% \mathrm{BaO}$, $3 \mathrm{wt} \% \mathrm{Fe}_{2} \mathrm{O}_{3}, 2 \mathrm{wt} \% \mathrm{Y}_{2} \mathrm{O}_{3}$ and $90 \mathrm{wt} \% \mathrm{Co}_{3} \mathrm{O}_{4}$ was obtained by conventional ceramic powder processing. Commercial $\mathrm{GDC}_{10}\left(10 \%\right.$ gadolinium-doped ceria, $\left.\mathrm{Ce}_{0.9} \mathrm{Gd}_{0.1} \mathrm{O}_{1.95}\right)$ electrolyte powder with a surface area of $10-14 \mathrm{~m}^{2} \mathrm{~g}^{-1}$ and particle size of $0.1-0.4 \mu \mathrm{m}$ was obtained from Fuel Cell Materials, USA.The NiO anode powder with a surface area of $2.9 \mathrm{~m}^{2} \mathrm{~g}^{-1}$ and particle size of $0.5-1.5 \mu \mathrm{m}$ was also sourced from Fuel Cell Materials, USA.

The cathode was a 50:50 mixture of BYCF and $\mathrm{GDC}_{10}$, while the anode was a 60:40 mixture of $\mathrm{NiO}$ and $\mathrm{GDC}_{10}$. These compositions were used to control and maintain the thermal expansion coefficient close to that of $\mathrm{GDC}_{10}$, which is $13.08 \times 10^{-6 \circ} \mathrm{C}^{-1}$ at $900^{\circ} \mathrm{C}[26]$.

The electrolyte powders were ground for $1 \mathrm{~h}$ and mixed with distilled water, including $10 \%$ polyvinyl alcohol as a binder, by weight. The binder-added powder was pelletized
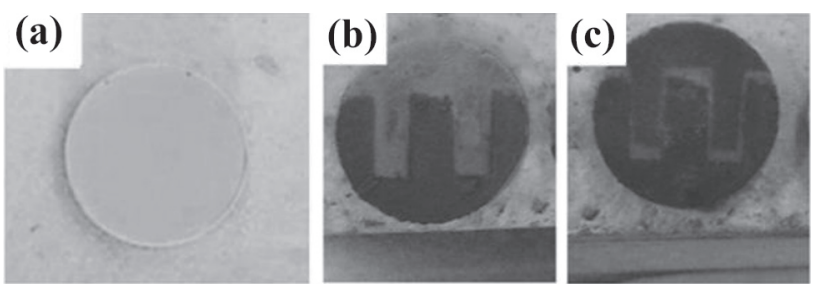

Figure 2. (a) $\mathrm{GDC}_{10}$ electrolyte. A uniaxial press was used to produce a pellet of $15 \mathrm{~mm}$ in diameter and $2 \mathrm{~mm}$ in thickness. (b) The SP technique was used to deposit a 50:50 BYCF + GDC $_{10}$ cathode on the electrolyte substrate. (c) The $\mu$-SOFC was completed by SP to deposit a $60: 40 \mathrm{NiO}+\mathrm{GDC}_{10}$ anode with rectangular 'teeth' on the electrolyte substrate.

with the help of hydraulic press machine. The cathode and anode mixtures were milled for $12 \mathrm{~h}$ in a cylindrical-capped container with alumina balls as filling with the help of a horizontal rotary ball mill and dried in an oven at $150^{\circ} \mathrm{C}$. The powders were ground again for $4 \mathrm{~h}$ in our in-house-made grinding machine and sieved through a 150 mesh.

In the SP technique, the spray gun was operated at $120 \mathrm{psi}$ air pressure and the nozzle was set up at a height of $20 \mathrm{~cm}$ with a $16 \mathrm{~cm}$ spraying diameter. The pellet was placed on a stainless steel substrate and temperature was increased to $450^{\circ} \mathrm{C}$. In order to use this technique, cathode and anode mixtures were needed in the form of slurries. The mixtures were mixed with distilled water in the ratio 30:70 vol\%. All slurries were milled for $12 \mathrm{~h}$ in a horizontal rotary ball mill for obtaining highly homogeneous slurries.

In order to prepare a $\mu$-SOFC sensor, the full fuel cell was fabricated with a 50:50 BYCF $+\mathrm{GDC}_{10}$ cathode and 60:40 $\mathrm{NiO}+\mathrm{GDC}_{10}$ anode deposited on the $\mathrm{GDC}_{10}$ electrolyte pellet $\left(50: 50 \mathrm{BYCF}+\mathrm{GDC}_{10}\left|60: 40 \mathrm{NiO}+\mathrm{GDC}_{10}\right| \mathrm{GDC}_{10}\right)$ as shown in figure 1 . The $\mathrm{GDC}_{10}$ powder was pressed to form pellets of $15 \mathrm{~mm}$ diameter and $2 \mathrm{~mm}$ thickness by using a uniaxial press under 3000 psi pressure. The $\mathrm{GDC}_{10}$ pellet, as seen in figure $2 \mathrm{a}$, was sintered at $1400^{\circ} \mathrm{C}$ with a heating rate of $10^{\circ} \mathrm{C} \mathrm{min}^{-1}$ for $10 \mathrm{~h}$. This $\mathrm{GDC}_{10}$ pellet shows high density for ion conduction at high temperatures [27]. The 50:50 BYCF $+\mathrm{GDC}_{10}$ cathode was deposited on the $\mathrm{GDC}_{10}$ electrolyte pellet by SP in which the rectangular saw-tooth shape sticker covered the surface to control the shape of the cathode layer. After spraying the cathode, this pellet was cosintered at $1100^{\circ} \mathrm{C}$ with a heating rate of $10^{\circ} \mathrm{C} \mathrm{min}^{-1}$ for $10 \mathrm{~h}$ as shown in figure 2b. Meanwhile a 60:40 NiO $+\mathrm{GDC}_{10}$ anode was also deposited on the $\mathrm{GDC}_{10}$ electrolyte pellet, opposite to the cathode area, by SP, where the rectangular saw-tooth shape sticker covered the cathode layer to control the shape of the anode, and provided a space between the anode and cathode area. In order to obtain high porosity for the adsorption of gas and increase the electrochemical power density [28,29], this pellet was co-sintered at $1100^{\circ} \mathrm{C}$ with a heating rate of $10^{\circ} \mathrm{C} \mathrm{m^{-1 }}$ for $10 \mathrm{~h}$ under an atmosphere as shown in figure $2 \mathrm{c}$. The symmetrical $\mu$-SOFC 
with a 50:50 BYCF+ GDC $10\left|50: 50 \mathrm{NiO}+\mathrm{GDC}_{10}\right| \mathrm{GDC}_{10}$ was fabricated using the same process as the full $\mu$-SOFC for measuring impedance spectra.

Figure 3 shows platinum electrodes as probes which were primed with platinum paste and pressed to ensure good contact. In the real experiment, the pellet with the platinum probes

(a)

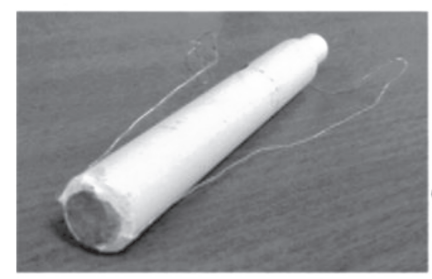

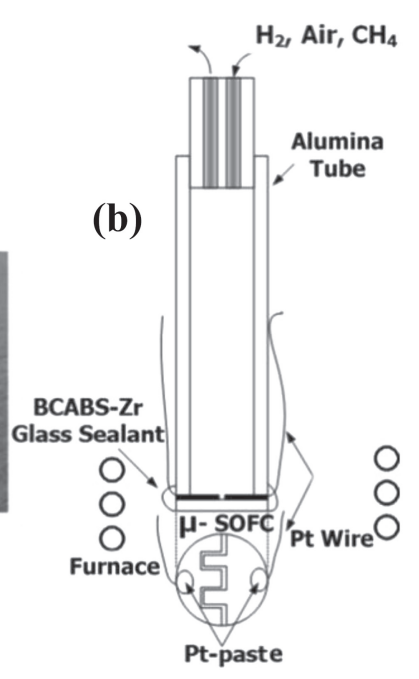

Figure 3. (a) The $\mu$-SOFC with an alumina tube and platinum wire. (b) Diagram showing the $\mu$-SOFC set-up for gas flow measurements. was placed in an in-house designed furnace. Microstructures were observed using a scanning electron microscope (SEM) (Gemini SEM, FE-SEM, and Zeiss). The ohmic and the interfacial resistance were determined by impedance spectroscopy using a Solarton 1286 electrochemical interface and a Solarton $1255 \mathrm{HF}$ frequency response analyser. These were interfaced with a computer in the frequency range from $0.01 \mathrm{~Hz}$ to $1 \mathrm{MHz}$. A PROVA 200A PV analyser was used to measure power density. The biogas composition $\left(\mathrm{H}_{2}, \mathrm{CO}_{2}, \mathrm{CH}_{4}, \mathrm{~N}_{2}\right.$ and $\left.\mathrm{H}_{2} \mathrm{~S}\right)$ was determined by gas chromatography with a flame thermal conductivity and photometric detector by using an Agilent GC7890. The mixture of gases used was $99.99 \%$ methane $\left(\mathrm{CH}_{4}\right)$ and $99.99 \%$ nitrogen $\left(\mathrm{N}_{2}\right)$, each at 60 psi pressure and mixed by a metreing valve from Swaglok as shown in figure $8 \mathrm{~b}$. The biogas was collected from a palm oil factory in the south of Thailand.

\section{Results and discussion}

The $\mu$-SOFC surface was examined using a SEM. Figure $4 \mathrm{a}$ shows the structure of the $\mu$-SOFC surface with anode and cathode deposited on the electrolyte. The space (electrolyte) separating the anode and cathode was a rectangular sawtooth shape on the $15 \mathrm{~mm}$ diameter electrolyte substrate. Figure $4 \mathrm{~b}$ shows the microstructure of the anode with $\sim 1 \mu \mathrm{m}$ pin-holes. Figure $4 \mathrm{c}$ shows the microstructure of the cathode

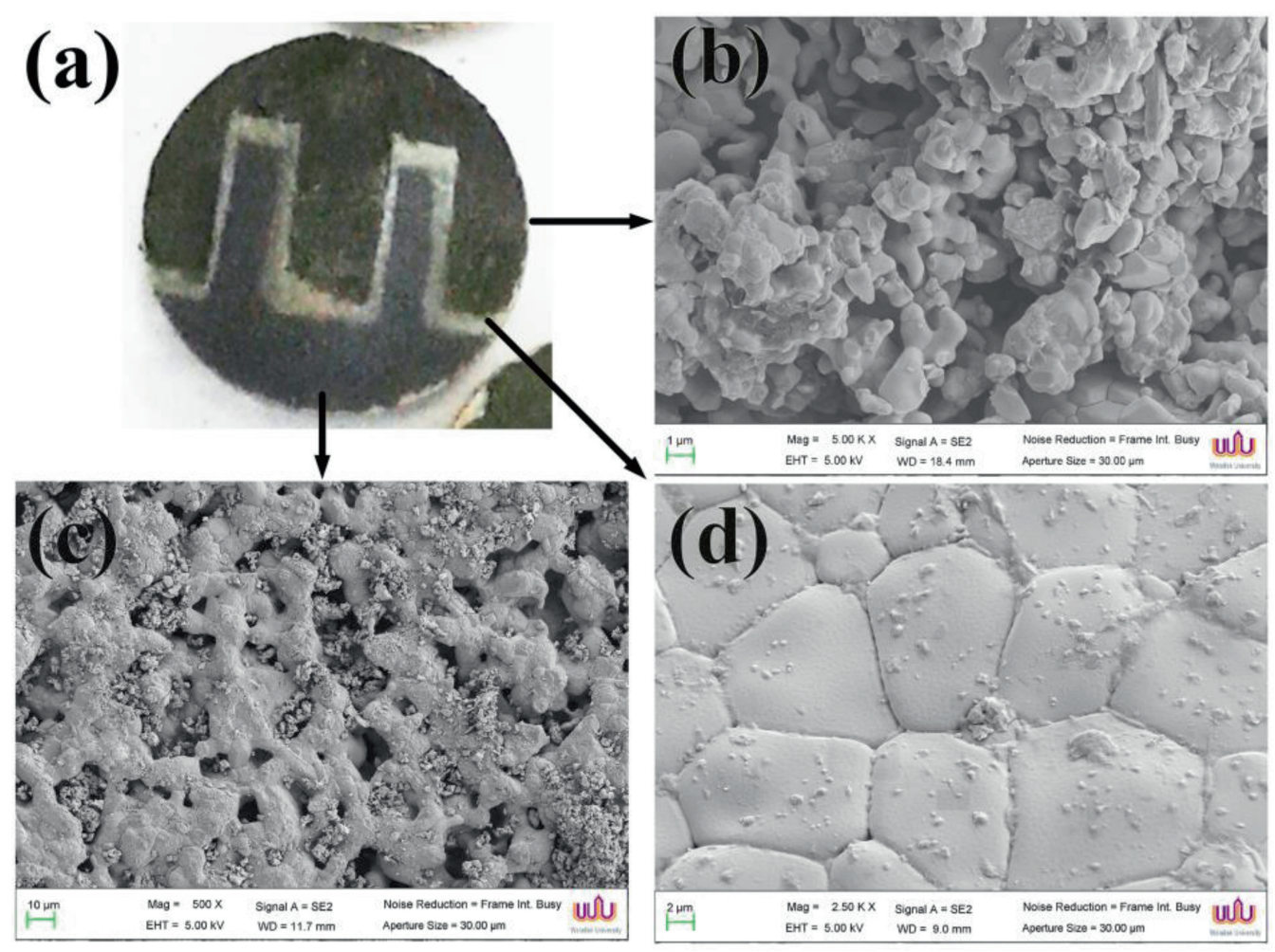

Figure 4. (a) The used $\mu$-SOFC after gas sensing. (b) Microstructure of the 60:40 NiO $+\mathrm{GDC}_{10}$ anode. (c) Microstructure of the 50:50 BYCF + GDC $_{10}$ cathode. (d) Microstructure of the GDC $_{10}$ electrolyte. 


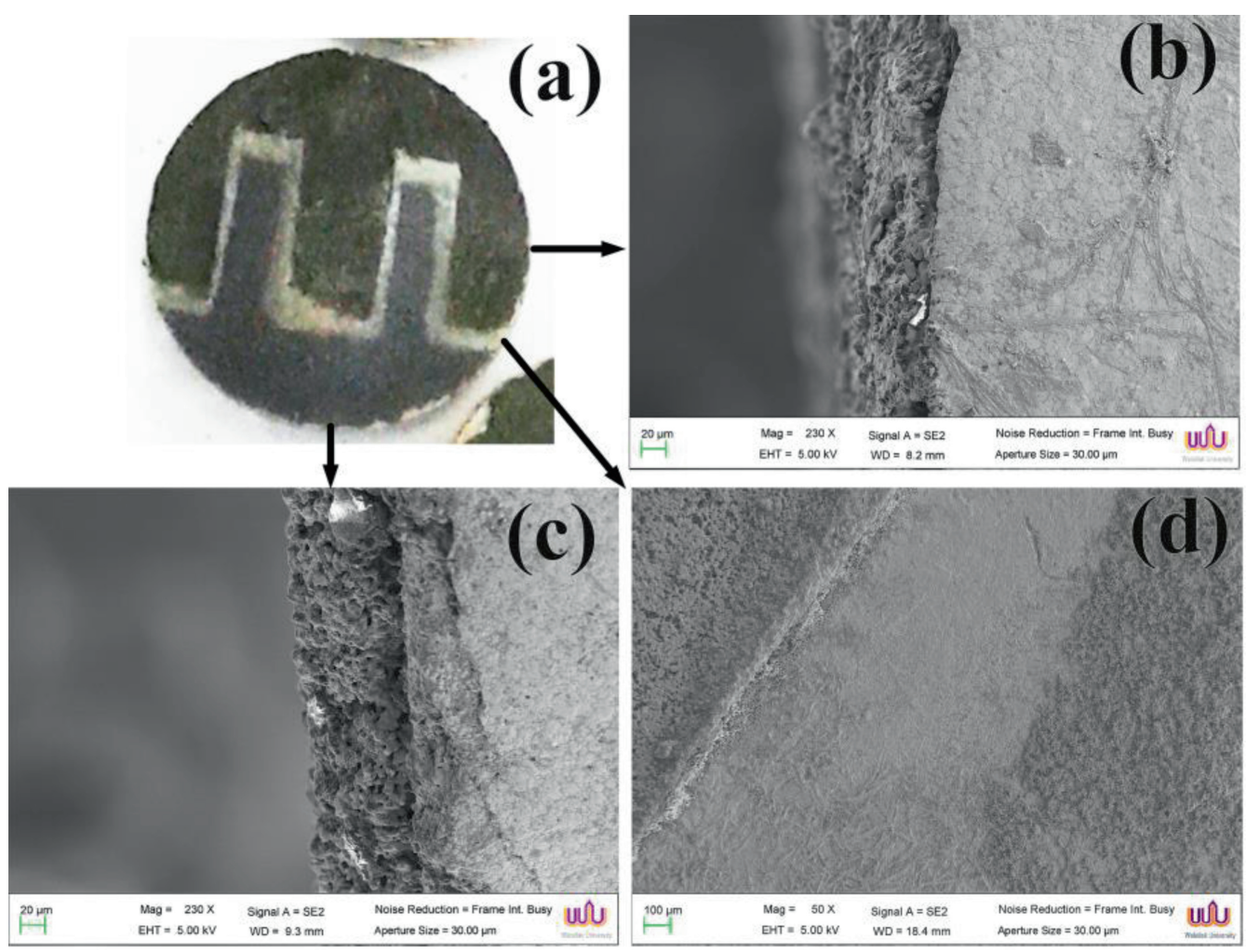

Figure 5. (a) The used $\mu$-SOFC after gas sensing. (b) Cross-section of the microstructure between the 60:40 $\mathrm{NiO}+\mathrm{GDC}_{10}$ anode and $\mathrm{GDC}_{10}$ electrolyte. (c) Cross-section showing the interface of the 50:50 BYCF + $\mathrm{GDC}_{10}$ cathode and the $\mathrm{GDC}_{10}$ electrolyte. (d) The free space separating the anode and cathode layers.
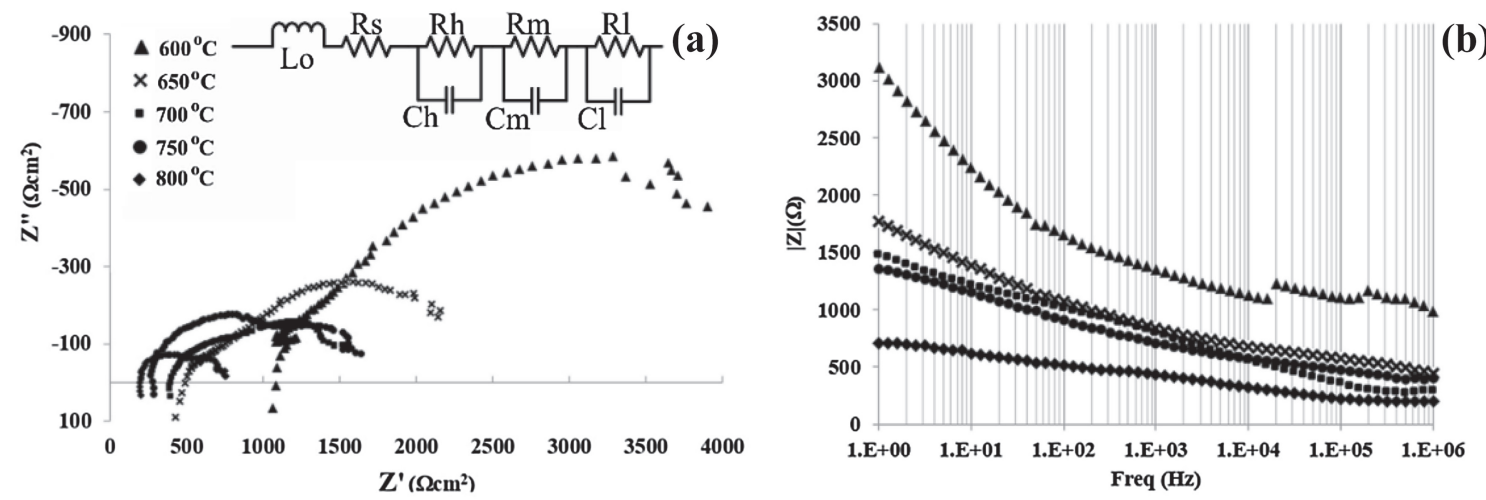

Figure 6. (a) Nyquist plots of the $\mu$-SOFC impedance spectra at various temperatures in the range of $550-800^{\circ} \mathrm{C}$. (b) Bode plots of the $\mu$-SOFC at various temperatures.

with $\sim 10 \mu \mathrm{m}$ pin-holes. High porosity was observed from the microstructure of the cathode and anode [27]. Figure $4 \mathrm{~d}$ shows the microstructure of the electrolyte with no pin-holes. This microstructure indicated that the electrolyte is highly dense. The deposited anode was $40 \mu \mathrm{m}$ in thickness on the electrolyte substrate (figure 5b). The deposited cathode was $80 \mu \mathrm{m}$ in thickness on the electrolyte substrate (figure 5c). SEM images clearly shows that the surfaces are well-connected to cathodeelectrolyte and anode-electrolyte interfaces (figure $5 \mathrm{~b}$ and c).
The free space on the electrolyte surface was $900 \mu \mathrm{m}$ wide between the anode and the cathode (figure $5 \mathrm{~d}$ ).

Impedance spectroscopy was utilized to assess the electrochemical properties and characteristics at different temperatures of the $\mu$-SOFC. The impedance spectra of BYCF$\mathrm{GDC}_{10}-\mathrm{NiO}$ are fitted using Zview software with a proper equivalent circuit model as shown in figure $6 \mathrm{a}$. In these models, $L_{\mathrm{o}}$ represents the inductance arising from equipment and cables during the measurements [28]. While $R_{\mathrm{S}}$ exhibits 


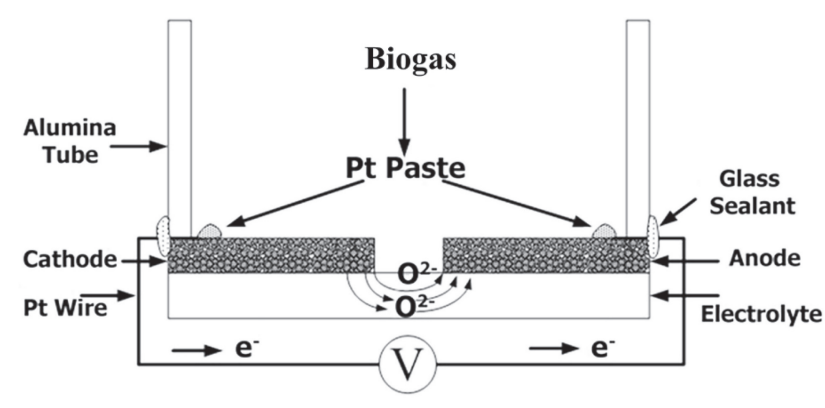

Figure 7. The conventional $\mu$-SOFC set-up for determining the $\mathrm{O}^{2-}$ ion flow.

the ohmic resistance caused by electrolyte $\mathrm{GDC}_{10}$ and wires [29]. According to Li et al, the components $\left(R_{1} C_{1}\right),\left(R_{\mathrm{m}} C_{\mathrm{m}}\right)$ and $\left(R_{\mathrm{h}} C_{\mathrm{h}}\right)$ exhibit reaction steps in the low-frequency (LF), medium-frequency (MF) and high-frequency (HF) range, respectively [30]. The results of Nyquist and Bode plots are shown in figure $6 a$ and $b$. An increase in temperature decreases the total impedance, depending on the electrical conductivity of the BYCF, NiO and $\mathrm{GDC}_{10}$ materials. The BYCF material shows high conductivity of $200-588.55 \mathrm{~S} \mathrm{~cm}^{-1}$ at $660-800^{\circ} \mathrm{C}$ and $3.23 \mathrm{eV}$ [31]. After oxidation at $500^{\circ} \mathrm{C}$, the $\mathrm{NiO}-\mathrm{GDC}_{10}$ substrate shows grain boundary (GB) and grain interior (GI) conductivities at 0.107 and $0.0009 \mathrm{~S} \mathrm{~cm}^{-1}$, respectively. The activation energies calculated from the Arrhenius plots for the GI and GB conductivities are 0.81 and
$0.9 \mathrm{eV}$, respectively [32]. Figure 6a also shows the characteristic of the $\mu$-SOFC at different operating temperatures. One large depressed arc is observed at 600 and $650^{\circ} \mathrm{C}$ and smaller arcs are observed when temperature is increased to 700, 750 and $800^{\circ} \mathrm{C}$. The $\mathrm{HF}\left(>10^{3} \mathrm{~Hz}\right)$ arcs correspond to the process of oxygen ionic exchange across the interfaces between the cathode and electrolyte [33]. The MF $\left(10^{3}-10^{2} \mathrm{~Hz}\right)$ arcs are probably associated with the diffusion of ion electrons at the surface of the cathode [28]. However, $\mathrm{LF}\left(<10^{2} \mathrm{~Hz}\right)$ arcs are related to oxygen gas phase diffusion through the porous cathode layer [28]. This reaction occurred at the cathode interfaced with electrolyte that acted on the one side of the electrolyte layer. Ion $\left(\mathrm{O}^{2-}\right)$ transferred across the gap between cathode and anode as shown in figure 7. The impedance arising from the gas phase diffusion not only corresponds to the temperature and diffusion coefficient of oxygen in air, but also involves the microstructure of the cathode. Therefore, the addition of $\mathrm{GDC}_{10}$ into BYCF can enhance the processes of oxygen ions and electrode reactions [33].

Moreover, $R_{\mathrm{h}}$ and $C_{\mathrm{h}}$ corresponded to the resistance and capacitance between the anode and electrolyte; $R_{\mathrm{m}}$ and $C_{\mathrm{m}}$ corresponded to the resistance between the cathode and electrolyte, while $R_{1}$ and $C_{1}$ corresponded to fuel gas-diffusion impedance [34] as shown in table 1 . The change in resistances $\left(R_{\mathrm{h}}, R_{\mathrm{m}}, R_{\mathrm{l}}\right)$ and capacitances $\left(C_{\mathrm{h}}, C_{\mathrm{m}}, C_{\mathrm{l}}\right)$ is dependent on the temperature, and the areas of the cathode/electrolyte/gas TPB active region [33].

The complex impedance of the $\mu$-SOFC was recorded over $600-800^{\circ} \mathrm{C}$. Figure $6 \mathrm{a}$ shows the usual three semicircles

Table 1. The fitting $R$ (resistance) and $C$ (capacitance) of impedance spectra for the symmetrical $\mu$ $\mathrm{SOFC}\left(\mathrm{BYCF}+\mathrm{GDC}_{10}\left|\mathrm{BYCF}+\mathrm{GDC}_{10}\right| \mathrm{GDC}_{10}\right)$ measured as a function of temperature in air.

\begin{tabular}{|c|c|c|c|c|c|c|c|}
\hline \multirow[b]{3}{*}{ Temperature $\left({ }^{\circ} \mathrm{C}\right)$} & \multicolumn{7}{|c|}{ Parameters } \\
\hline & \multicolumn{4}{|c|}{$R\left(\Omega \mathrm{cm}^{2}\right)$} & \multicolumn{3}{|c|}{$C\left(\mathrm{~F} \mathrm{~cm}^{2}\right)$} \\
\hline & $R_{\mathrm{S}}$ & $R_{1}$ & $R_{\mathrm{m}}$ & $R_{\mathrm{h}}$ & $C_{1}$ & $C_{\mathrm{m}}$ & $C_{\mathrm{h}}$ \\
\hline 600 & 1100 & 800 & 1500 & 650 & $1.205 \times 10^{-06}$ & $2.552 \times 10^{-05}$ & $1.552 \times 10^{-08}$ \\
\hline 650 & 580 & 400 & 550 & 200 & $1.205 \times 10^{-06}$ & $2.552 \times 10^{-04}$ & $1.552 \times 10^{-08}$ \\
\hline 700 & 400 & 180 & 120 & 200 & $6.184 \times 10^{-03}$ & $1.184 \times 10^{-08}$ & $1.184 \times 10^{-05}$ \\
\hline 750 & 260 & 15 & 65 & 60 & $7.184 \times 10^{-02}$ & $1.004 \times 10^{-07}$ & $1.184 \times 10^{-04}$ \\
\hline 800 & 150 & 6 & 8 & 27 & $1.918 \times 10^{-01}$ & $1.004 \times 10^{-06}$ & $1.184 \times 10^{-04}$ \\
\hline
\end{tabular}

Table 2. Chemical composition of biogas from the palm oil factory in the south of Thailand.

\begin{tabular}{lcccccc}
\hline Gas & Samples & $\mathrm{H}_{2}(\%$ volume $)$ & $\mathrm{N}_{2}(\%$ volume $)$ & $\mathrm{CH}_{4}(\%$ volume $)$ & $\mathrm{CO}_{2}(\%$ volume $)$ & $\mathrm{H}_{2} \mathrm{~S}(\mathrm{ppm})$ \\
\hline Biogas & 1 & 0.000 & 5.286 & 61.072 & 35.333 & 923.893 \\
& 2 & 0.000 & 4.921 & 60.592 & 34.781 & 953.304 \\
Average & 3 & 0.000 & 4.793 & 58.336 & 34.886 & 956.115 \\
Standard deviation & & 0.000 & 5.000 & 60.000 & 35.000 & 944.437 \\
& & \pm 0.000 & \pm 0.256 & \pm 1.461 & \pm 0.293 & \pm 17.847 \\
\hline
\end{tabular}

GC was used for measurement. 


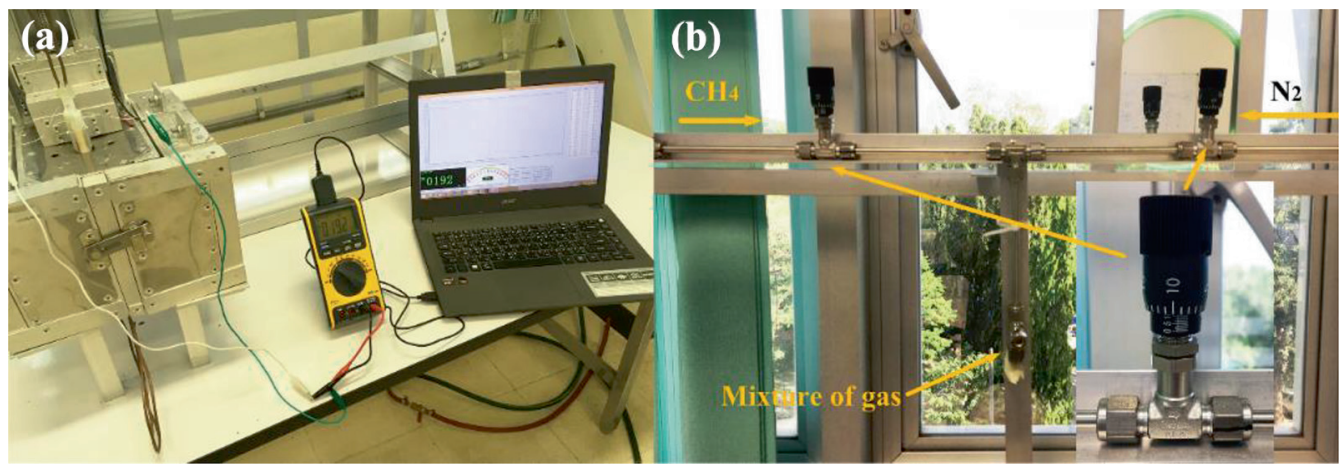

Figure 8. (a) The $\mu$-SOFC sensor was set-up in the furnace for application of the gas sensing. (b) The conventional gas mixing technology by using metring valve to mix the $\mathrm{CH}_{4}$ and $\mathrm{N}_{2}$ gas.

in the complex impedance corresponding to the cathodeelectrolyte and electrolyte-anode interfacial impedance contributions to the total impedance of the system. The total impedance decreases with frequency and temperature as shown in figure $6 \mathrm{~b}$. It is affected by porous-media transport, elementary heterogeneous chemical reaction, ion conduction and electrochemical charge transfer, as shown in equation (1):

$$
Z_{\mathrm{tot}}=Z_{\mathrm{rd}}+\frac{R_{\mathrm{ct}, \mathrm{a}}}{i+j \omega R_{\mathrm{ct}, \mathrm{a}} C_{\mathrm{dl}, \mathrm{a}}}+R_{\mathrm{ele}}+\frac{R_{\mathrm{ct}, \mathrm{c}}}{i+j \omega R_{\mathrm{ct}, \mathrm{c}} C_{\mathrm{dl}, \mathrm{c}}}
$$

Here, $C_{\mathrm{dl}, \mathrm{a}}$ and $C_{\mathrm{dl}, \mathrm{c}}$ are the double layer capacitances at the anode-electrolyte and cathode-electrolyte interfaces respectively; $R_{\mathrm{ct}, \mathrm{a}}$ and $R_{\mathrm{ct}, \mathrm{c}}$ are the charge transfer resistances at the anode and cathode respectively; $R_{\text {ele }}$ is the ohmic resistance of the electrolyte; $Z_{\mathrm{rd}}$ is the effective reaction-diffusion resistance and $\omega=2 \pi f$ is the angular frequency [34].

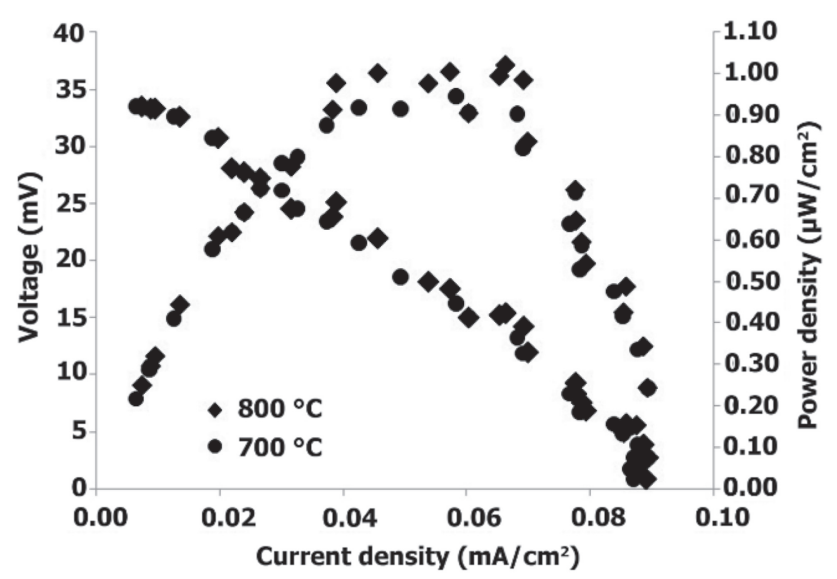

Figure 9. Current-voltage characteristics of biogas from the palm oil factory in the south of Thailand and the corresponding power densities for the $\mu$-SOFC with a flow rate of $\mathrm{CH}_{4}=0.21 \mathrm{~min}^{-1}$ at $700-800^{\circ} \mathrm{C}$.
Therefore, the frequency also affects the total impedance through capacitances.

The biogas, as the fuel for the sensor was collected from a palm oil factory in the south of Thailand. Table 2 indicates that the biogas was measured three times by GC machine which contains $\mathrm{N}_{2}, \mathrm{CH}_{4}, \mathrm{CO}_{2}$ and $\mathrm{H}_{2} \mathrm{~S}$. The average biogas composition was $5 \% \mathrm{~N}_{2}, 60 \% \mathrm{CH}_{4}$ and $35 \% \mathrm{CO}_{2}$ by $\%$ volume. Hydrogen sulphide $\left(\mathrm{H}_{2} \mathrm{~S}\right)$ was obtained in biogas in the small amount of $944.437 \mathrm{ppm}$ due to the palm wood materials. Lau et al [35] reported that biogas produced by palm oil mill effluent anaerobic digestion contains small amounts of $\mathrm{H}_{2} \mathrm{~S}$. Figure 8a shows the set-up for measuring the voltage generated by the $\mu$-SOFC sensor at $700-800^{\circ} \mathrm{C}$ temperature of the furnace. The calibration on the $\mu$-SOFC sensor needs various percentages of $\mathrm{CH}_{4}$ to generate the voltage because biogas from the factory contains $60 \% \mathrm{CH}_{4}$. Therefore, calibration of the sensor was conducted at various percentage levels of methane gas as shown in figure $8 \mathrm{~b}$. Figure 9 exhibits power density and voltage as a function of biogas, the palm factory, fed to the sensor at 700 and $800^{\circ} \mathrm{C}$. The maximum power density of the $\mu$-SOFC sensor was $1.00 \mu \mathrm{W} \mathrm{cm}{ }^{-2}$ at 700 and $800^{\circ} \mathrm{C}$. This means almost the same power density generated at both temperatures. Therefore, the $\mu$-SOFC sensor can be operated at $700^{\circ} \mathrm{C}$ to save on energy consumption as well as thermal stress relief. Le et al [36] observed

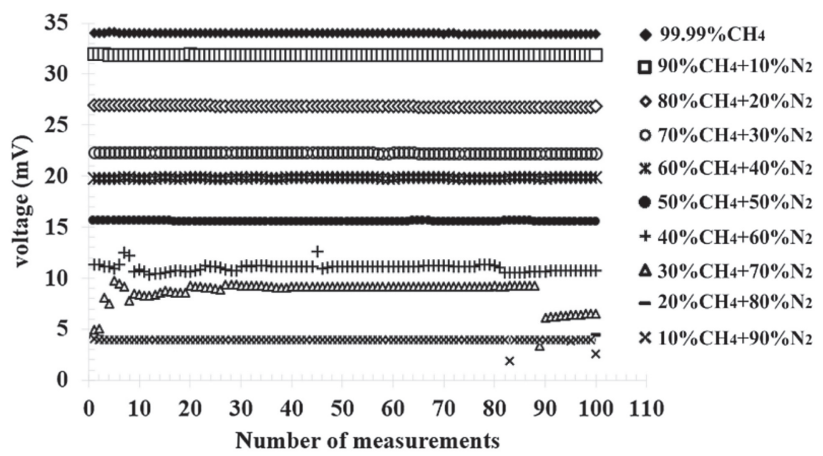

Figure 10. Measured voltage levels for different gas mixtures fed to the $\mu-\mathrm{SOFC}$ at $800^{\circ} \mathrm{C}$ with the gas flow rate of $0.21 \mathrm{~min}^{-1}$. 


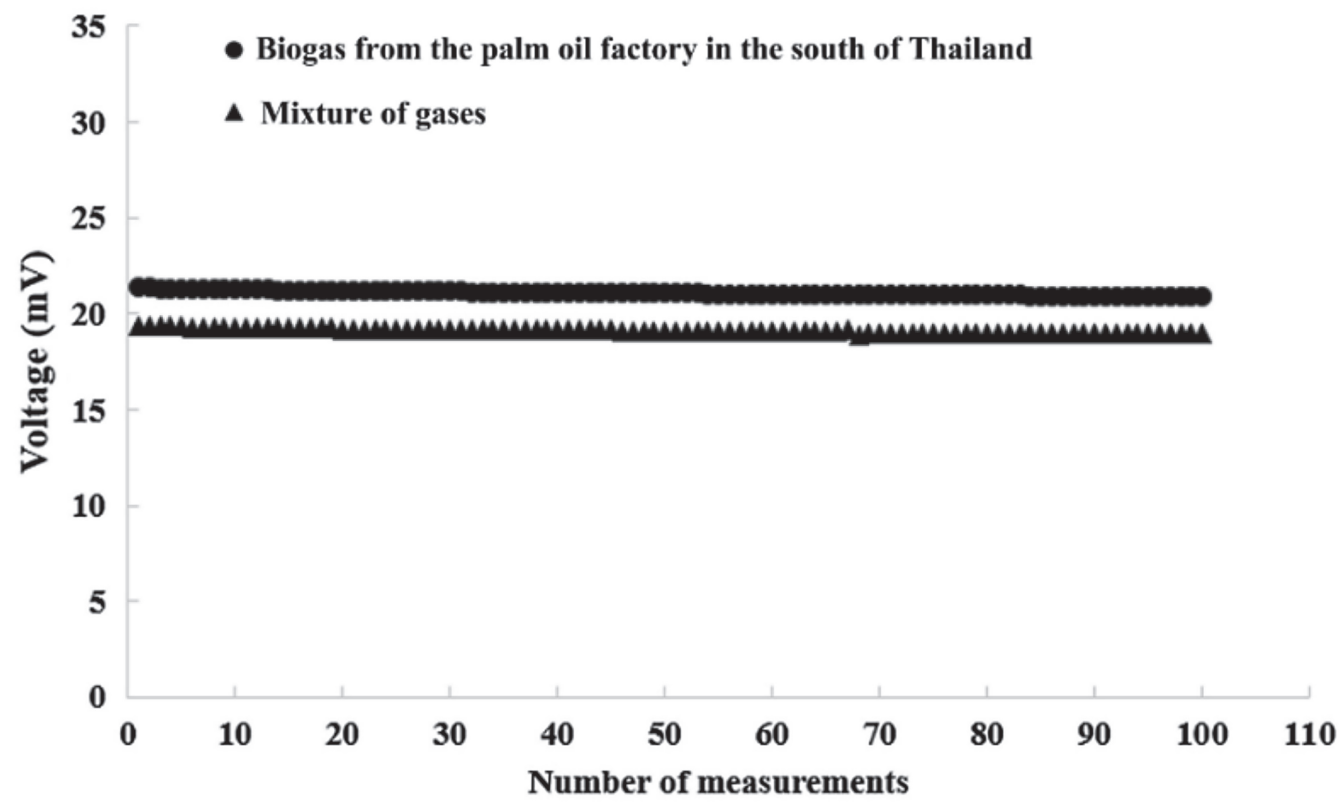

Figure 11. Comparison of voltage levels of biogas from the palm oil factory in the south of Thailand and the mixture of gases measured by the $\mu$-SOFC at $800^{\circ} \mathrm{C}$, with a flow rate of $0.21 \mathrm{~min}^{-1}$.

a power density of $0.26 \mathrm{~W} \mathrm{~cm}^{-2}$ from the full fuel cell fabricated from $\mathrm{Ba}_{0.5} \mathrm{Sr}_{0.5} \mathrm{Co}_{0.8} \mathrm{Fe}_{0.2} \mathrm{O}_{3}$ (BSCF) + GDC cathode, $\mathrm{La}_{1.8} \mathrm{Dy}_{0.2} \mathrm{Mo}_{0.2} \mathrm{O}_{9}(\mathrm{LDM})$ electrolyte and $\mathrm{GDC}+\mathrm{NiO}+$ LDM anode which operated in an atmospheric reactant with a 1.5:1 $\left(\mathrm{CH}_{4}: \mathrm{O}_{2}\right)$ ratio. At high temperatures, the composition of the BSCF + GDC cathode reacted to thermal expansions; however, it performed steadily in the temperature range of $652-700^{\circ} \mathrm{C}$.

The measured voltage levels correspond to the amount of methane gas fed to the sensor. Experiments used mixture of gases which involves percentages of $\mathrm{CH}_{4}$ and $\mathrm{N}_{2}$ varying from 10 to $99.99 \%$. The voltage levels of $50 \% \mathrm{CH}_{4}$ to $99.99 \% \mathrm{CH}_{4}$ were highly stable and can be used for reference. Meanwhile the voltage levels of $30 \% \mathrm{CH}_{4}$ to $40 \% \mathrm{CH}_{4}$ were unstable and had high error levels. For $10 \% \mathrm{CH}_{4}$ to $20 \% \mathrm{CH}_{4}$, it was not possible to separate the exact voltage level as shown in figure 10. There are three-layer fuel cells of $\mathrm{BSCF} / \mathrm{GDC} / \mathrm{NiO}$ which have a current level of around $0.55 \mathrm{~A} \mathrm{~cm}^{2}$ spending $200 \mathrm{~h}$, based on a $700 \mathrm{mV}$ voltage level at $550^{\circ} \mathrm{C}$ [37]. Therefore, the $\mu$-SOFC is a potential option for $\mathrm{CH}_{4}$ gas detectors at high temperature.

There is insufficient methane to react in the reforming to convert $\mathrm{CH}_{4}$ to hydrogen when the $\mathrm{CH}_{4}$ concentration was below $40 \%$ (equation (2)). Hence, a low voltage level was detected with high error levels. $\mathrm{CH}_{4}$ quantity should be sufficient to produce a typical endothermic reaction at high temperatures of $700-900^{\circ} \mathrm{C}$. High catalysts are required to promote the conversion of syngas when the NiO-based material is used. Other reactions also occur concurrently during the dry reforming process. One typical side chemical reaction is a reverse water gas shift which can reduce the $\mathrm{H}_{2} / \mathrm{CO}$ ratio in the syngas product. This chemical reaction contributes to proper adjustment of the $\mathrm{H}_{2} / \mathrm{CO}$ ratio for production of higher hydrocarbons [38].

Biogas was compared with the mixture of gases as shown in figure 11. Biogas-generated voltage level is $20.90 \mathrm{mV}$ while the mixture was reported at $18.84 \mathrm{mV}$ (figure 11). All gas samples were measured under the same conditions. The biogas from the factory was higher than the mixture of gas by around $10.93 \%$, because $\mathrm{H}_{2}$ was reformed from $\mathrm{CH}_{4}$ gas on the anode side and mixed with the air in the alumina tube chamber. The $\mathrm{NiO}$ composition included in the anode side of the $\mu$-SOFC, activated and contributed to $\mathrm{CH}_{4}$-dry reforming as shown in equation (2) [5]. The biogas from the factory contained higher $\mathrm{CO}_{2}$ levels than the mixture of gas, and $\mathrm{H}_{2} \mathrm{~S}$ was also detected in biogas. It may also be the case that $\mathrm{H}_{2} \mathrm{~S}$ causes the generation of the $\mathrm{H}_{2}$ which is used by $\mathrm{CH}_{4}$ dry reforming to produce the voltage, but it has a very small effect. Normally, the SOFC technology can produce the electricity (voltage level; $\mathrm{e}^{-}$) by $\mathrm{H}_{2}$ and $\mathrm{O}_{2}$, following $\mathrm{H}_{2}+\mathrm{O}^{2-} \rightarrow \mathrm{H}_{2} \mathrm{O}+2 \mathrm{e}^{-}$and $1 / 2 \mathrm{O}_{2}+\mathrm{e}^{-} \rightarrow \mathrm{O}^{2-}$. Therefore, the biogas from factory can produce high voltage levels that occurred in the chemical reaction following equation (2):

$$
\mathrm{CH}_{4}+\mathrm{CO}_{2} \leftrightarrow 2 \mathrm{CO}+2 \mathrm{H}_{2}
$$

Therefore, $\mathrm{CH}_{4}$ is used to generate electricity using the $\mu$ SOFC. A $\mu$-SOFC with small-sized pellets cannot produce enough electricity to act as a power source. However, $\mu$-SOFC can still be used as a low-cost sensor for $\mathrm{CH}_{4}$ in biogas. 


\section{Conclusions}

A novel $\mu$-SOFC, consisted of a 50:50 BYCF + GDC 10 cathode and 60:40 $\mathrm{NiO}+\mathrm{a} \mathrm{GDC}_{10}$ anode deposited on a $\mathrm{GDC}_{10}$ electrolyte substrate in rectangular saw-tooth shapes, was fabricated. This $\mu$-SOFC only allowed the fuel gas to be fed on one side and produced microwatt power density. $\mathrm{CH}_{4}$ gas generated with $1 \mu \mathrm{W} \mathrm{cm} \mathrm{cm}^{-2}$ of power density and the device can be adapted to a low-cost sensor for detecting methane in the biogas which contains $\mathrm{H}_{2} \mathrm{~S}, \mathrm{CO}_{2}, \mathrm{~N}_{2}$ and $\mathrm{CH}_{4}$ with $\mathrm{CH}_{4}$ the major component at $60 \%$ (based on biogas from oil palm wood). The sensor was monitored in terms of voltage level corresponding to the quantity of $\mathrm{CH}_{4}$ in the biogas. This sensor cannot represent accurate voltage levels for $10-40 \% \mathrm{CH}_{4}$. The $\mu$-SOFC sensor can be usefully operated at high temperatures which would be suitable in gas forming systems and biogas power plants. The electronic sensors are sensitive to humidity, which affects both metals and semiconductors. In contrast, the $\mu$-SOFC can be operated at comparatively high temperatures and is mainly ceramic. Therefore, the novel $\mu$ SOFC has potential for use as a low-cost sensor to detect biogas composition.

\section{Acknowledgements}

This research was supported by the Innovation Fund (RDO590769S), Prince of Songkla University. We thank our colleagues from the Faculty of Engineering; PSU Energy Systems Research Institute (PERIN), Centre of Excellence in Materials Engineering (CEME) and Centre for Advanced Material and Energy Sciences (CAMES, Universiti Brunei Darrusalam) and all those who provided their insight and expertise that greatly assisted this research.

\section{References}

[1] Charnnok B, Suksaroj T, Boonswang P and Chaiprapat S 2013 Bioresour. Technol. 131492

[2] Chaiprapat S, Wongchana S, Loykulnant S, Kongkaew C and Charnnok B 2015 Process Saf. Environ. Prot. 94420

[3] Choosong T, Phakthongsuk P, Tekasakul S and Tekasakul P 2014 Saf. Health Work 586

[4] Chaikitkaew S, Kongjan P and Thong S O 2015 Energy Procedia 79838

[5] González-Gil R, Herrera C, Larrubia M Á, Kowalik P, Pieta I S and Alemany L J 2016 Int. J. Hydrog. Energy 4119781

[6] Tuna C E, Silveira J L, da Silva M E, Boloy R M, Braga L B and Pérez N P 2018 Int. J. Hydrog. Energy 432108

[7] Bornapour M, Hooshmand R-A, Khodabakhshian A and Parastegari M 2016 Energy 117176

[8] Rottmayer M, Singh R and Huang H 2016 J. Power Sources 332139
[9] Timurkutluk B, Timurkutluk C, Mat M D and Kaplan Y 2016 Renew. Sustain. Energy Rev. 561101

[10] Patil T C and Duttagupta S P 2016 Appl. Energy 168 534

[11] Pla D, Sánchez-González A, Garbayo I, Salleras M, Morata A and Tarancón A 2015 J. Power Sources 293264

[12] Wang J 2015 Energy 80509

[13] Sohn S, Baek S M, Nam J H and Kim C-J 2016 Int. J. Hydrog. Energy 415582

[14] Kim K-J, Choi S-W, Kim M-Y, Lee M-S, Kim Y-S and Kim H-S 2016 J. Ind. Eng. Chem. 4269

[15] Yao C, Meng J, Liu X, Zhang X, Liu X, Meng F et al 2015 Solid State Sci. 4990

[16] Jin F, Liu J, Shen Y and He T 2016 J. Alloys Compd. 685 483

[17] Yi S, Shen Y, Zhao H, Du Z, Chen N and Huang B 2016 Electrochim. Acta 219394

[18] Patro P K, Delahaye T and Bouyer E 2010 Solid State Ion. 181 1378

[19] Handal H T and Thangadurai V 2014 Solid State Ion. 262 359

[20] Doraswami U, Shearing P, Droushiotis N, Li K, Brandon N P and Kelsall G H 2011 Solid State Ion. 192494

[21] Mukhopadhyay M, Mukhopadhyay J, Sharma A D and Basu R N 2011 Int. J. Hydrog. Energy 367677

[22] Ding J, Li X, Cao J, Sheng L, Yin L and Xu X 2014 Sens. Actuators B 202232

[23] Vuong N M, Hieu N M, Hieu H N, Yi H, Kim D, Han Y-S et al 2014 Sens. Actuators B 192327

[24] Assar M and Karimzadeh R 2016 J. Colloid Interface Sci. 483 275

[25] Hing P 2015 ECS Conference on Electrochemical Energy Conversion \& Storage with SOFC-XIV (July 26-31, 2015), ECS

[26] Wongthong P, Nakason C, Pan Q, Rempel G L and Kiatkamjornwong S 2015 J. Appl. Polym. Sci. 13242520

[27] Hanifi A R, Laguna-Bercero M A, Sandhu N K, Etsell T H and Sarkar P 2016 Sci. Rep. 627359

[28] Pang S, Jiang X, Li X, Wang Q and Su Z 2012 J. Power Sources 20453

[29] Çelikbilek Ö, Siebert E, Jauffrès D, Martin C L and Djurado E 2017 Electrochim. Acta 2461248

[30] Li R, Ge L, Chen H and Guo L 2012 Electrochim. Acta 85273

[31] Suklueng M, Yoong V N, Hing P and Ming L C 2014 Walailak J. Sci. Technol. (WJST) 12373

[32] Chourashiya M G and Jadhav L D 2011 Int. J. Hydrog. Energy 3614984

[33] Pang S, Jiang X, Li X, Wang Q and Su Z 2012 Int. J. Hydrog. Energy 372157

[34] Huang Q-A, Hui R, Wang B and Zhang J 2007 Electrochim. Acta $\mathbf{5 2} 8144$

[35] Ohimain E I and Izah S C 2017 Renew. Sustain. Energy Rev. 70242

[36] Le M-V, Tsai D-S and Nguyen T-A 2018 Ceram. Int. 441726

[37] Kim C, Park H, Jang I, Kim S, Kim K, Yoon H et al 2018 J. Power Sources 378404

[38] Gao Y, Jiang J, Meng Y, Yan F and Aihemaiti A 2018 Energy Convers. Manage 171133 